\title{
How Does Project Supervisor Maintain Sustainability of Project Members? A Study from Leadership Perspective
}

\author{
Han-Sheng Lei, Chuan-Fu Lai * and Chih-Chang Chen \\ Department of Business Administration, National Yunlin University Science \& Technology, 123 University Road, \\ Section 3, Douliou, Yunlin 64002, Taiwan; hslei@yuntech.edu.tw (H.-S.L.); \\ andrew_chen_1828@yahoo.com.tw (C.-C.C.) \\ * Correspondence: d10522007@yahoo.com
}

Received: 8 July 2018; Accepted: 3 August 2018; Published: 6 August 2018

\begin{abstract}
Project members' innovative behavior is crucial to their sustainability and successful implementation of the project. This research develops a conceptual model to explore the effect of project supervisor leadership skills on member's innovative behavior. The model is examined by a sample of 437 project members in Taiwan. The results show that project supervisors' emotional healing positively influences members' innovative behavior through affect-based trust in their supervisor and supervisor conceptual skill has an inverted-U impact on members' innovative behavior through cognition-based trust in their supervisor. This paper further discusses implications of these conclusions for additional research on the association between leadership skills and innovative behavior.
\end{abstract}

Keywords: emotional healing; conceptual skill; affect-based trust; cognition-based trust; innovative behavior

\section{Introduction}

Project members' innovative behavior can keep their sustainable performance and career, furthermore, it is important to the project development of an organization [1]. Innovative behavior refers to generating and implementing new useful ideas [2], which is also viewed as a driver of sustainable competitive advantage of cooperation. Individual innovativeness has been viewed as a critical contributor to project development and organizational survival. Although the integral role of supervisors in stimulating innovative behavior of members of a group [3,4], there is, as far as we are aware, few studies that have explored the impact of supervisor's leadership skills on project members' innovative behavior. Insight into project supervisor leadership skills that enhance the innovative contributions made by project members is one of the aims of this paper.

The early examination of leadership behaviors included a separation of those behaviors into relationship-oriented and task-oriented categories. Relationship-oriented leadership needed skills focus on improving the quality of the relationship with followers, whereas, task-oriented leadership needed skill focus on the task to be accomplished [5]. Conceptual skill is a core skill of task-oriented leadership and emotional healing skill is a core skill of relation-oriented leadership (Yukl, 2012). Therefore, in this paper, we focus on two core leadership concepts found in the functional perspective literature, namely emotional healing and conceptual skill [6,7] (Dacher, 1999; Sturnick, 1998). Most existing research concentrates on examining linear relationships between supervisor leadership and individual outcomes [8,9]. But there might exist a curvilinear relationship between supervisor conceptual skill and followers' innovative behavior, because high conceptual skill may lead employees to be overly dependent on their supervisor, which inhibits their generation of creative ideas. It means 
that the effect of conceptual skill and emotional healing skill on follower's innovative behavior may be different. Therefore, we will examine different impacts of the two core leadership skills on innovative behavior.

Furthermore, the two concepts are considered as crucial for leader effectiveness in terms of promoting subordinates' trust in leaders [6-10]. Cognitive-based trust and affect-based trust-two dimensions of trust—can be considered to be the mediator between the two leadership skills and project member innovative behavior, because the two dimensions of trust are the direct outcomes of the two supervisors' leadership skills. Cognitive-based trust is created by subordinates' perceptions that their direct supervisor understands the work that being done by subordinates and is aware of the subordinates' working conditions [8]. Affect-based trust involves perceptions of the supervisor's personal investment in the well-being of the subordinates [11]. Several studies revealed that affect-based and cognition-based trust in a leader have different impacts on individual outcomes (e.g., Yang and Mossholder, 2010 [12]; Ng and Chua, 2006 [13]). Therefore, we considered affect-based trust mediates the linear relationship between supervisor emotional healing skills and project member innovative behaviors and cognition-based trust mediates the inverted U-shaper between conceptual skills and innovative behavior.

We will test our hypotheses in the context of project. There are three contributions of this study at least. First, we found that supervisor's conceptual skill and emotional healing skill has different impact on project member innovative behavior, specifically, conceptual skill has an inverted U-shape effect on project member innovative behavior and emotional healing skill has positive linear effect on project member innovative behavior. Second, we find that these two different relationships are mediated by cognition-based trust and affect-based trust respectively. The third contribution is exploring how to generate and implement new useful ideas from members in project setting.

\section{Theory and Hypothesis}

\subsection{Project Supervisor Skills and Project Members Innovative Behavior}

Leadership skills have been viewed as a critical factor for fostering trust in an organizational context, including both trust among followers and trust between followers and their leader [14,15]. We proposed that emotional healing and conceptual skill, two core leadership skills representing relationship-oriented leadership and task-oriented leadership skill respectively, influence follower's innovative behavior in different ways.

Numerous scholars have argued that emotional healing is a crucial skill for leader's effectiveness [6,7]. Emotional healing described as an ability to recognize when and how to facilitate the process of healing. It included a leader's ability to foster a follower's spiritual recovery from hardship and trauma [16]. This type of leadership skill was viewed as highly empathetic and as an ability to show sensitivity to others [16]. They created a safe environment that enabled their followers to voice personal and professional concerns [16]. Scholars have recognized the need for supervisor was able to help followers recover hope, overcome broken dreams and repair severed relationships [6,7]. Weymes (2003) [17] suggested that healing emotions and feelings to shape employees' emotions towards the organization is the major purpose of leadership. Supervisors should be empathetic and create an environment for subordinates to express feelings or emotions during periods of organizational difficulty [10]. Healing is similar to the need for humility, acceptance, forgiveness [18]; it is an important aspect of leadership skill [19]. Emotional healing refers to the act of showing sensitivity to others' personal concerns $[19,20]$ and has the ability to identify when and how to promote the healing process.

This paper proposed that project supervisor emotional healing might promote followers' innovative behavior. Innovative behavior infers to generate and implement new useful ideas in workplace [2]. Project supervisor emotional healing behaviors describes a leader commit to and skill in fostering spiritual recovery from hardship or trauma, which can help project member cover negative emotion. Individual who has positive emotion will allocates more vigor to solve problem in their 
tasks [21]. Additionally, project supervisor emotional healing can create climate that are safe for project member to voice more personal and professional new useful ideas freely according to the viewpoint proposed by Liden et al. (2008) [20] and Liden et al. (2014) [19]. Then, project members can receive more information from other colleagues, which can facilitate the generation of new useful ideas. In this context, they also would be safe to generate and implement new useful ideas, which be conceptualized as innovative behavior. Thus, we hypothesize:

Hypothesis 1. Project supervisor's emotional healing is positively associated with project members innovative behavior.

Supervisor conceptual skill is defined as possessing the competence that they can provide support and assistance to others effectively, especially immediate followers demanded by organization or tasks [20]. Supervisors who have high level conceptual skill can emphasize clarity around problems, goals and strategic direction, then helping followers to recognize where they are going and how to achieve success $[20,22]$.

Accordingly, project supervisor with moderate level of conceptual skill can provide direction and assistance of solving problem to project members. It ensures that project members understand what is expected of leaders and learn skills to attack the problem. Increasing project supervisor conceptual skill provides more useful information, ideas or knowledge to project members. Increasing project members' access to information, ideas of task are crucial to generating new useful ideas as it increases the opportunity to acquire specific assets needed by innovativeness [23].

Although supervisor conceptual skill may facilitate the emergence of ideas for improvement, leaders exhibiting high level of conceptual skill would not be associated with efficiency and incremental improvements. Because project supervisor competence of solving problem may lead subordinates to form excessive trust and psychological dependence that hinder project members deeper thought for solutions of completing project [13]. We expect, therefore, that high levels of conceptual with a focus on problem solving would decrease employee motivation to pay effort to solve job-related problems. A moderate degree of supervisor conceptual skill directs employee to learn ways of solving problems from their supervisor $[24,25]$. Therefore, there will be a limit promoting effect of project supervisor conceptual skill that any given project members can accept and no guarantee that any particular level of project supervisor conceptual skill will be optimal for project members innovative behavior.

Although project supervisor conceptual skill positive affects subordinate innovative behavior, the relationship is not strictly linear according to the findings in $\mathrm{Ng}$ and Chua (2006) [13]. As noted above, providing direction, information and ideas might result in excessive trust and psychological dependence, which can lead subordinate to be unwilling to cost time, energy to think new useful solutions of project-related problem. Marginally, higher level of supervisor conceptual skill begins to decrease effort to deepened thought that are beneficial to generate new useful ideas [23,26]. The more psychological dependence on project supervisor, the less the effort project members can pay to innovative activities. Yet too low level of supervisor conceptual skill may limit project members innovative behavior because of insufficient new useful information, knowledge and ideas provided by project supervisor [27]. Although project supervisor conceptual skill increases project members' potential for generating and implementing new useful ideas and increasing project supervisor conceptual skill will eventually result in less new useful ideas generation and implementation of project members. Thus, we hypothesize:

Hypothesis 2. There is an inverted U-shape relationship between project supervisor conceptual skill and project members innovative behavior. 


\subsection{Trust in the Project Supervisor and Project Members Innovative Behavior}

Affect-based trust was defined emotional bonds between individuals $[28,29]$. It focuses on affiliation, empathy, rapport that based on individual shared concern of each other [8]. Hansen, Morrow and Batista (2002) [30] argue that affect-based trust is subjective perception in nature, because it is based on the moods, feelings or emotions that one has concerning the perceived trustworthiness of an individual, group or organization. Some findings show that affect-based trust in a supervisor leads to positive outcomes, such as role-related performance [9,31], organizational identification [9] and normal commitment [31]. This paper will discuss the positive impact of affect-based trust in project supervisor on project members innovative behavior from psychological safety perspective.

From psychological safety perspective, project member who has a strong and favorable affective connection with their supervisor, as manifests high level affect-based trust, will perceived safety between their interactions [8]. Therefore, project members with a high-level trust in their project supervisor often express ideas freely and share information proactively, which in turn may lead to the project supervisor giving more feedback ideas and information that can lead to generation of more new useful ideas. Furthermore, as project members' psychological safety brought by affect-based trust, they may also involve in exploratory behaviors and promote learning [9], which is an important component of innovativeness [32]. Therefore, we proposed that affect-based trust in project supervisor positive influence project members innovative behavior. Thus, we hypothesize:

Hypothesis 3. Project member affect-based trust in their supervisor is positively associated with their innovative behavior.

Cognition-based trust in leader refers to trust based on performance-related cognitions such as leader's competence, reliability, dependability and responsibility [8,29]). Subordinate's beliefs on the leader's competence were viewed as an important component of cognition-based trust in leader. Several research findings show that cognitive-based trust has limited benefits (e.g., $\mathrm{Ng}$ and Chua, 2006 [13]) or even negative consequences (e.g., Kramer, 1999 [33]; Langfred, 2004 [34]). We will discuss the inverted U-shape relationship between cognition-based trust in project supervisor and project member innovative behavior.

$\mathrm{Ng}$ and Chua (2006) [13] proposed that researchers can explain the impact mechanism of cognition-based trust using 'criticality calculation' principle on the basis of social decision heuristics. It refers to have an instrumental quality that include profit maximization and cost minimization (e.g., Weber, 1978 [35]). This heuristic is rooted in a motivation to complete individual's goals in the most efficient way and provides some channeling principles. A core principle for contributing under this heuristic principle is that the one must benefit from others' achievement. It means that the one will decrease contribution if he cannot obtain personal gain from others' achievement. On the contrary, if the one's personal gains are anticipated form others' achievement, he will make the least contribution required to facilitate others achieve its goal. Altogether, individuals who adopt this heuristic demarcate the lowest level of contribution they viewed it as crucial to help others bridge its gap so as to complete its goal, therefore, the individuals can also profit form the others.

How does this heuristic explain the effect of cognition-based trust in project supervisor on project members innovative behavior? The project member with cognition-based trust in their supervisor will apply 'criticality calculation' principle to allocate their resources [13]. According to this principle, there are two reasons to explain why project members should be indisposition to make contribution to their project supervisor if cognition-based trust in supervisor is low. First, project members' contribution alone might be insufficient to achieve job goal. Second, even if project members' effort does help achieve job goal, project member loses out because project supervisor will profit from his/her effort. As cognition-based trust in supervisor increases, project member is more likely to pay more effort to solve job-related problems because they will not be afraid that project supervisor will free-ride on their contribution. Furthermore, project member will also obtain personal gains from their individual 
achievement via helping to address supervisor's project goal. However, if cognition-based trust in leader increases to the more degree, which suggest that project supervisor will contribute significantly to the project-related goals, project members may be psychological dependence on their leader and then reduce their effort to solve project-related problems. It is because project members do not perceive their efforts as crucial to achieve the project-related goal any more, which in turn allocate resources to other activities (e.g., Kerr and Bruun, 1983 [36]) to maximize their personal gains. Therefore, we expect that there is an initial positive relationship between cognition-based trust in leader and project members innovative behavior; we also expected that increasing cognition-based trust in project supervisor will eventually result in less project members innovative behavior. Thus, we hypothesize:

Hypothesis 4. There will be an inverted U-shape relationship between cognition-based trust in project supervisor and project members innovative behavior.

\subsection{Mediating Effect of Trust in Project Supervisor}

Emotional healing was conceived as sensitivity to others' personal concerns and has the capability to identify when and how to provide the healing to others $[19,20]$. It emphasizes on empathy and creating an environment for subordinates to express their negative emotions [10]. Emotional healing behaviors of supervisor focus on providing psychological welfare to subordinate by conveying caring to subordinates, minimizing negative emotion. McAllister (1995) [28] argued that the others who behave in an altruistic and caring manner, the essence of emotional healing behavior, toward oneself will increase the level of affect-based trust in him or her.

Although researchers have tested the impact of supervisor emotional healing (as an important dimension of servant leadership) on organizational citizenship behavior [20,37,38], few studies have examined the linkages between supervisor emotional healing skill and individual outcomes (e.g., innovative behavior). As proposed by McAllister (1995) [28] and Yang and Mossholder (2006) [29], individual A treat individual B by a caring manner, the individual B would promote affect-based trust in individual $A$ and individual $B$ tend to infer that he was in a psychologically safe environment in which individual B is more likely to speak their ideas and share information freely. Emotional healing fits description of the type of leadership skill. Accordingly, if a project supervisor behaves in an emotional healing or caring way toward project members, it will promote project members' affect-based trust in their supervisor. Simultaneously, project members will perceive that they are in a psychologically safe environment and be more likely to express their ideas and share information, which in turn may lead to the project supervisor providing more feedback ideas and information that might help generate more new useful ideas. Therefore, we infer that emotional healing skill of project supervisor promote such affect-based trust in project supervisor, in turn, project members innovative behavior. Thus, we hypothesize:

Hypothesis 5. Project supervisor emotional healing behavior is positively related to project members innovative behavior through the mediating effect of affect-based trust in project supervisor.

Cognition-based trust is more objective in nature and is based on a rational and methodical process that results in a judgment that an individual is trustworthy [19]. The followers obtain support and useful knowledge from supervisor and finally solve the problem and get improvement of their performance. The followers may feel the sense of achievement; they know their leader be trustworthy while they need some skills to solve problems, which conceptualized as cognition-based trust. Therefore, supervisor conceptual skill is a critical antecedent of cognition-based trust in leader.

Researchers have previously investigated that a leader's ability and skills can establish trust and researchers also found that trust in a leader mediated the relationship between leadership and subordinates' attitudes and outcomes $[39,40]$. In this article, we proposed that the U-shape impact of project supervisor conceptual skill on project members innovative behavior is conveyed 
through cognition-based trust. According to 'criticality calculation' principle proposed by Ng and Chua (2006) [13], if the cognition-based trust in project supervisor leaded by their conceptual skill is low, the project member may decrease their effort to project-related goal. Because they consider their contribution alone might be insufficient to achieve job goal (e.g., research targets). As project supervisor's conceptual skill-closely related to cognition-based trust-increases, project members will allocate more energy to their project goals as they believed that they can benefit from project supervisor conceptual skill. However, if project members excessively trust in their supervisor based on leader's competence and skills, they will psychologically rely on their supervisor and decrease their effort to project-related goals. Thus, we proposed Hypothesis 6 and Research model was depicted in Figure 1.

Hypothesis 6. Cognition-based trust mediates the inverted U-shape relationship between project supervisor conceptual skill and project members innovative behavior.

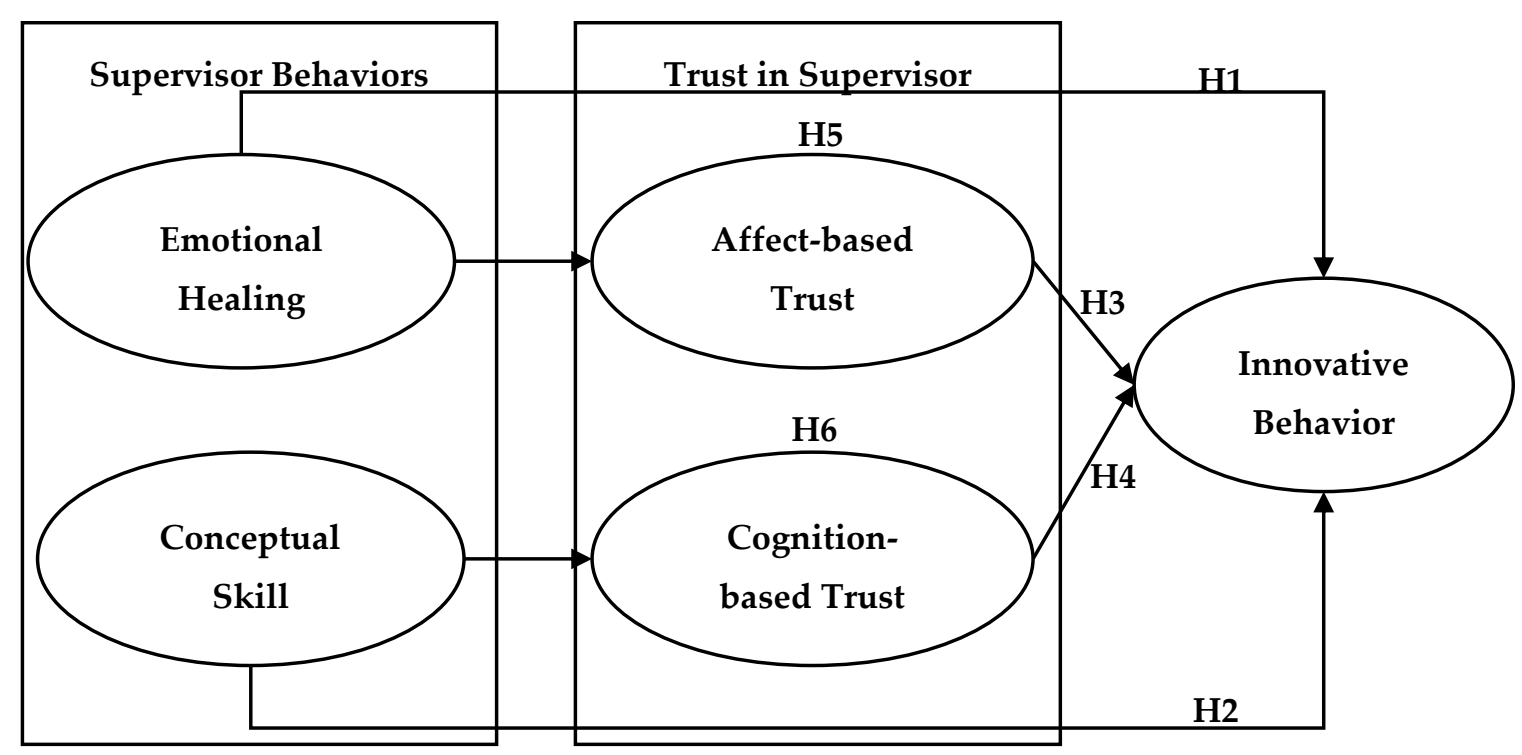

Figure 1. Research Model (Note: H1-H6 are Hypothesis 1-Hypothesis 6 respectively).

\section{Methods}

\subsection{Sample and Data Collection}

We collected data from project leaders and members in a larger firm in Taiwan between August 2017 and December 2017. The Vice Department Head help us to conduct this field survey. We collected data from two sources: project member and their direct supervisor. The project members questionnaire includes emotional healing, conceptual skill, cognition-based trust, affect-based trust and the project supervisor questionnaire includes innovative behavior and background information. We distributed the set of questionnaires to the project supervisor and the supervisor distributed the project member questionnaire to their subordinates.

The dyads questionnaires were distributed to 497 project members and their direct supervisor and 437 completed questionnaires were returned. Of the 437 respondents, 246 were male ( 56.23 percent). The average age was $37.44(\mathrm{SD}=6.26)$ and the average tenure was $11.53(\mathrm{SD}=6.49)$. For education of the 437 project members, $8.92 \%$ had a College degree, $45.66 \%$ had a bachelor degree, $44.39 \%$ had a postgraduate degree and $1.14 \%$ had received a doctoral education. 


\subsection{Measures}

All measures were translated from English into Chinese language. Following the back-translation procedure recommended by Brislin (1986) [41], a senior PhD student translated the original English measurement into Chinese and a professor who focused on organizational behavior research back translated from Chinese to English. Finally, in order to address the discrepancies, the both English vision and Chinese vision were checked and modified by a bilingual organizational behavior scholar. All measurements rated by project members or supervisor using 5-point Likert-type scale ranging from 1 (strongly disagree) to 5 (strongly agree).

\subsubsection{Emotional Healing}

A 4-item scale that was extracted from Liden et al. (2008) [20] was used to measure project supervisor emotional healing. The original emotional healing scale was a dimension of servant leadership developed by Liden et al. (2008) [20]. Sample items were "My supervisor cares about my personal well-being" and "My supervisor can recognize when I'm down without asking me". Cronbach's alpha of this scale was 0.89 .

\subsubsection{Conceptual Skill}

We also used 4-item scale that was extracted from Liden et al. (2008) [20] to measure project supervisor conceptual skill. The original conceptual skill scale was a dimension of servant leadership that developed by Liden et al. (2008) [20]. Sample items were "My supervisor can tell if something is going wrong" and "My supervisor can solve work problems with new or creative ideas." Cronbach's alpha of this scale was 0.92 .

\subsubsection{Affect-Based Trust}

We used 5-item scale originally developed by Yang and Mossholder (2006) [29] to measure project members affect-based trust. Samples items includes "If you share your problems with supervisor, you know he will respond caringly" "You can talk freely to supervisor about your difficulties and know that he will want to listen." Cronbach's alpha of this scale was 0.87 .

\subsubsection{Cognition-Based Trust}

We used 4-item scale originally developed by Yang and Mossholder (2006) [29] to measure project members cognition-based trust. Samples items include "I can rely on supervisor to do a major portion of the group work" "Supervisor was the person you can trust to get the work done". Cronbach's alpha of this scale was 0.88 .

\subsubsection{Innovative Behavior}

We used 6-item scale originally developed by Scott and Bruce (1994) [2] to measure project member innovative behavior. Two sample items are "searches out new technologies, processes, techniques, and/or product ideas" and "generates creative ideas." The coefficient alpha reliability of innovative behavior is 0.91 .

\subsubsection{Control Variables}

We controlled for project members demographics (e.g., gender, age, education, tenure) that a likely to influence their innovative behavior $[42,43]$ to rule out the alternative explanation of the relationship between core variables in this paper. Age and company tenure are self-reported in years, education is self-reported in experience of education and gender was dummy coded, with female coded as 1 and male coded as 0 . 


\section{Results}

\subsection{Confirmatory Factor Analysis}

AMOS 17.0 was used to conduct confirmatory factor analysis examining the validity of these constructs. Table 1 shows the results of confirmatory factor analysis. The baseline measurement model fits the data well: $\chi^{2}(220)=899.98, \mathrm{IFI}=0.90, \mathrm{TLI}=0.89, \mathrm{CFI}=0.90, \mathrm{RMSEA}=0.05, \mathrm{SRMR}=0.05$.

Table 1. The Comparison of The Measurement Models.

\begin{tabular}{|c|c|c|c|c|c|c|c|c|}
\hline Models & Factors & $x^{2}$ & Df & IFI & TLI & CFI & RMSEA & SRMR \\
\hline Baseline model & Five factors & 899.98 & 220 & 0.90 & 0.89 & 0.90 & 0.05 & 0.05 \\
\hline Model 1 & Four factors:EH and CS were combined & 1195.32 & 224 & 0.86 & 0.84 & 0.86 & 0.10 & 0.06 \\
\hline Model 2 & Four factors:AT and CT were combined & 1029.26 & 224 & 0.88 & 0.87 & 0.88 & 0.09 & 0.05 \\
\hline Model 3 & Four factors:EH and AT were combined & 1512.85 & 224 & 0.81 & 0.79 & 0.81 & 0.12 & 0.07 \\
\hline Model 4 & Four factors:CS and CT were combined & 1184.14 & 224 & 0.86 & 0.84 & 0.86 & 0.10 & 0.06 \\
\hline Model 5 & Two factors: EH, CS, AT and CT were combined & 1846.90 & 229 & 0.77 & 0.74 & 0.76 & 0.13 & 0.08 \\
\hline Model 6 & One factor: all constructs were combined & 2220.68 & 230 & 0.71 & 0.68 & 0.71 & 0.14 & 0.09 \\
\hline
\end{tabular}

Note: $\mathrm{EH}=$ Emotional Healing, CS = conceptual skill, AT = Affect-based Trust, CT = Cognition-based Trust.

Furthermore, we compare the baseline measurement model to alternative competition models to examine whether some other models perform better fit than baseline model (see Table 1). The results of confirmatory factor analysis reveal that no alternative models yielded better chi-square or fit index of baseline model, indicating that our baseline model was a better measurement model.

\subsection{Correlation Analysis}

Means, standard deviation and correlations of the key constructs were shown in Table 2. Based on the results, project supervisor emotional healing was positively related to project members affect-based trust $(r=0.50, p<0.01)$ and innovative behavior $(r=0.63, p<0.01)$. Supervisor conceptual skill was positively related to project member cognition-based trust $(\mathrm{r}=0.71, p<0.01)$. The correlations between each two constructs are consistent with our hypothesis and provided initial support for our hypotheses.

Table 2. Mean, Standard errors and correlations.

\begin{tabular}{|c|c|c|c|c|c|c|c|c|c|c|c|}
\hline & Mean & SD & 1 & 2 & 3 & 4 & 5 & 6 & 7 & 8 & 9 \\
\hline 1 Gender & 0.44 & 0.43 & & & & & & & & & \\
\hline 2 Age & 37.44 & 6.26 & -0.07 & & & & & & & & \\
\hline 3 Education & 2.24 & 0.59 & $-0.12 *$ & $-0.17^{* *}$ & & & & & & & \\
\hline 4 Tenure & 11.53 & 6.49 & -0.01 & $0.80^{* *}$ & $-0.20^{* *}$ & & & & & & \\
\hline $5 \mathrm{EH}$ & 3.18 & 0.74 & -0.08 & -0.03 & $0.15^{* *}$ & -0.02 & $(0.89)$ & & & & \\
\hline $6 \mathrm{CS}$ & 3.45 & 0.77 & $-0.13^{* *}$ & -0.01 & $0.12 * *$ & -0.02 & $0.66^{* *}$ & $(0.92)$ & & & \\
\hline $7 \mathrm{AT}$ & 3.47 & 0.72 & $-0.13^{* *}$ & 0.05 & 0.04 & 0.06 & $0.50 * *$ & $0.57 * *$ & $(0.87)$ & & \\
\hline $8 \mathrm{CT}$ & 3.48 & 0.79 & -0.08 & 0.06 & 0.07 & 0.04 & $0.58^{* *}$ & $0.71^{* *}$ & $0.75^{* *}$ & $(0.88)$ & \\
\hline 9 IB & 3.38 & 0.61 & -0.12 & 0.02 & 0.12 & 0.03 & $0.63^{* *}$ & $0.67^{* *}$ & $0.55^{* *}$ & $0.60 * *$ & $(0.91)$ \\
\hline
\end{tabular}

Note: ${ }^{*} p<0.05 ;{ }^{* *} p<0.01 ; \mathrm{EH}=$ Emotional Healing, $\mathrm{CS}=$ conceptual skill, AT $=$ Affect-based Trust, $\mathrm{CT}=$ Cognition-based Trust, IB = Innovative Behavior.

\subsection{Hypothesis Testing}

We conducted hierarchical multiple regression using SPSS 23.0 to test our hypothesis, the results are shown in Table 3. In model 3, we entered control variables and project supervisor emotional healing and found that emotional healing was positively and significantly associated to project members innovative behavior $(\beta=0.62, p<0.01$ ), hypothesis 1 was supported. In model 6 , we entered control variables and conceptual skill into regression equation and found that project supervisor conceptual skill was positively related to project members innovative behavior $(\beta=0.66, p<0.01)$, furthermore, after we entered the squared term of conceptual skill and found that this term was negatively associated to project members innovative behavior (model $7, \beta=-0.16, p<0.01$ ), hypothesis 2 was supported. The findings confirmed that project supervisor conceptual skill was beneficial to project members 
innovative behavior to a certain extent and harmful more than this point. The inverted U-shape relationship between project supervisor conceptual skill and project members innovative behavior are showed in Figure 2.

Table 3. Regression Analysis.

\begin{tabular}{|c|c|c|c|c|c|c|c|c|c|c|}
\hline \multirow{2}{*}{ Variable } & \multirow{2}{*}{$\begin{array}{c}\text { AT } \\
\text { Model } 1\end{array}$} & \multirow{2}{*}{$\begin{array}{c}\text { CT } \\
\text { Model } 2\end{array}$} & \multicolumn{8}{|c|}{ IB } \\
\hline & & & Model 3 & Model 4 & Model 5 & Model 6 & Model 7 & Model 8 & Model 9 & Model 10 \\
\hline Gender & $-0.09 *$ & 0.02 & -0.07 & -0.04 & -0.04 & -0.03 & -0.03 & -0.07 & -0.08 & -0.04 \\
\hline Age & -00.1 & 0.06 & 0.01 & -0.01 & 0.01 & -0.02 & -0.04 & -0.05 & -0.07 & -0.06 \\
\hline Education & -0.03 & -0.01 & 0.02 & 0.09 & 0.03 & 0.04 & 0.04 & 0.07 & 0.06 & 0.03 \\
\hline Tenure & -0.07 & 0.01 & 0.05 & 0.02 & 0.02 & 0.07 & 0.09 & 0.07 & 0.07 & 0.08 \\
\hline EH & $0.49 * *$ & & $0.62 * *$ & & $0.47^{* *}$ & & & & & \\
\hline CS & & $0.71^{* *}$ & & & & $0.66^{* *}$ & $0.62 * *$ & & & $0.46^{* *}$ \\
\hline $\mathrm{CS}^{*} \mathrm{CS}$ & & & & & & & $-0.16^{* *}$ & & & -0.08 \\
\hline AT & & & & 0.54 ** & $0.31 * *$ & & & & & \\
\hline $\mathrm{CT}$ & & & & & & & & $0.59 * *$ & $0.52 * *$ & $0.20^{* *}$ \\
\hline $\mathrm{CT}^{*} \mathrm{CT}$ & & & & & & & & & -0.18 ** & -0.11 * \\
\hline$R^{2}$ & $0.26^{* *}$ & $0.51 * *$ & $0.41 * *$ & $0.32 * *$ & $0.48^{* *}$ & $0.45^{* *}$ & $0.47^{* *}$ & $0.37^{* *}$ & $0.40^{* *}$ & 0.50 ** \\
\hline
\end{tabular}

Note: $\mathrm{N}=438, * p<0.05,{ }^{* *} p<0.01$. EH $=$ Emotional Healing, $\mathrm{CS}=$ conceptual skill, AT $=$ Affect-based Trust, $\mathrm{CT}=$ Cognition-based Trust, IB = Innovative Behavior.

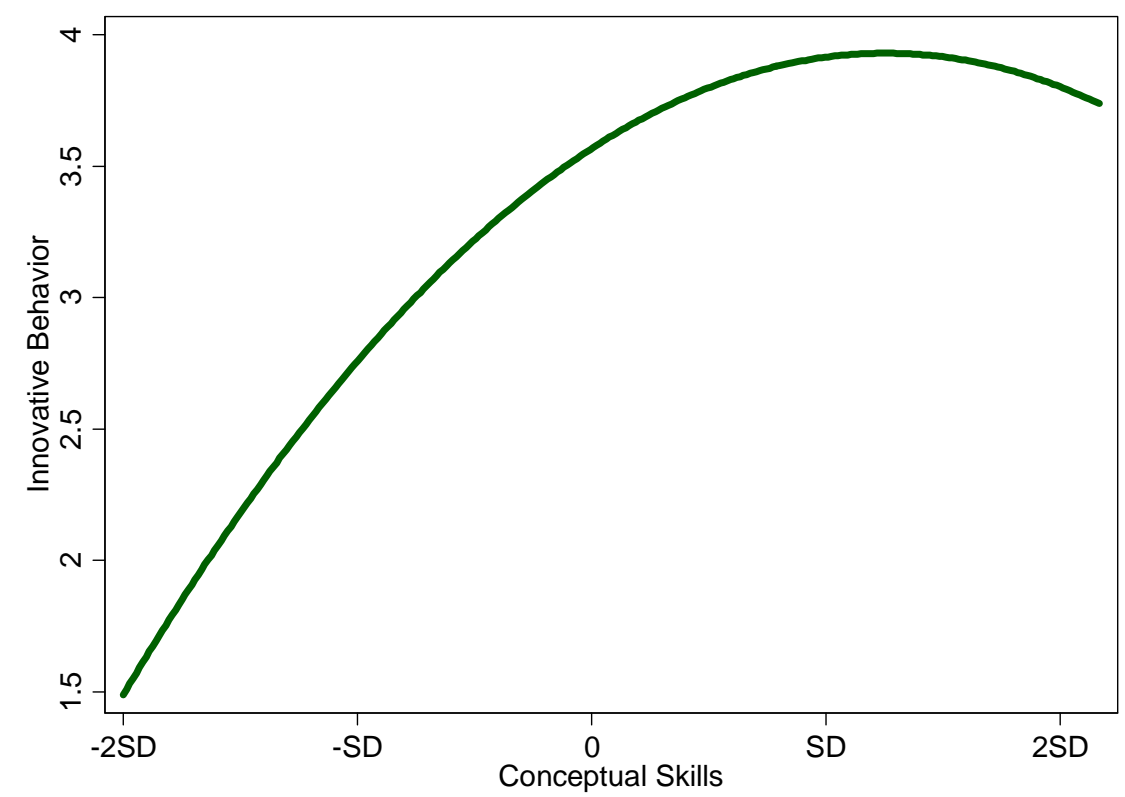

Figure 2. The inverted U-shape relationship between conceptual skill and innovative behavior.

In model 4, we entered control variables and supervisor emotional healing and found that affect-based trust was positively and significantly associated to project members innovative behavior ( $\beta=0.54, p<0.01)$, hypothesis 3 was supported. In model 8 , we entered control variables and cognition-based trust and found that project supervisor cognition-based trust was positively related to project members innovative behavior $(\beta=0.59, p<0.01)$, furthermore, we entered the squared term of cognition-based trust and found that this term was negatively associated to project members innovative behavior (model $9, \beta=0.18, p<0.01$ ), hypothesis 4 was supported. The findings confirmed that cognition-based trust was beneficial to project members innovative behavior to a certain extent and harmful more than the point. The inverted U-shape relationship between cognition-based trust and project members innovative behavior are showed in Figure 3. 


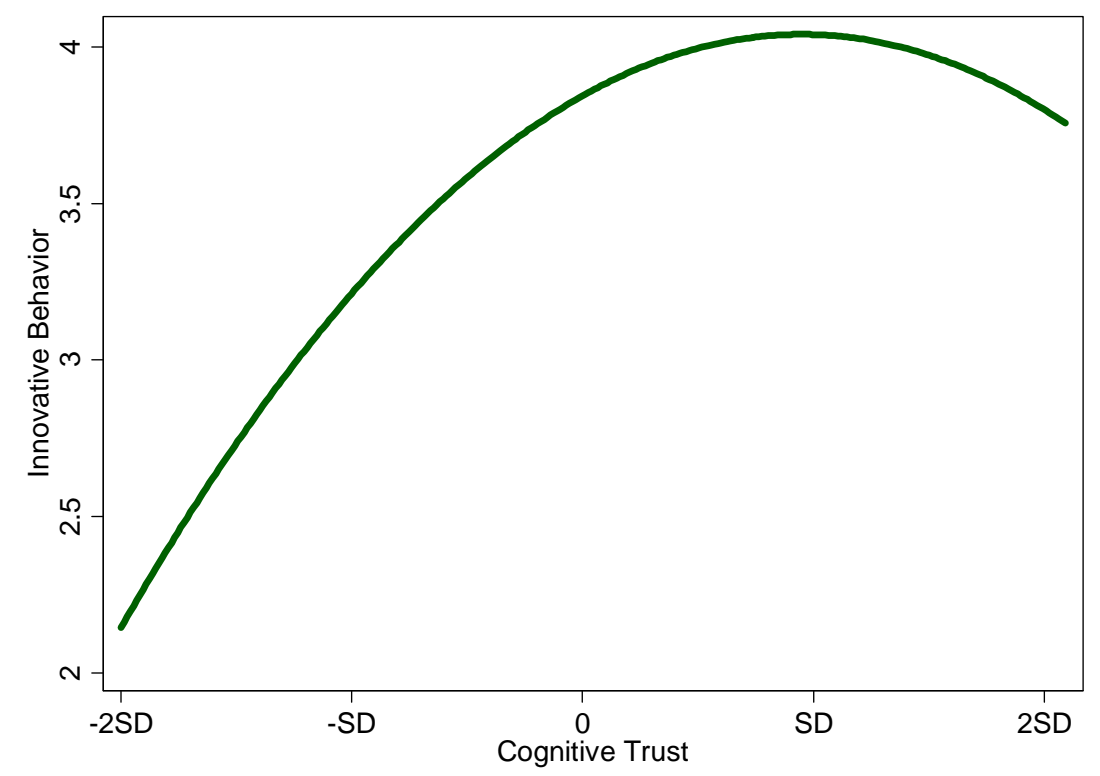

Figure 3. The inverted U-shape relationship between cognition-based trust and innovative behavior.

To test the mediating effect of affect-based trust on relationship between project supervisor emotional healing and project members innovative behavior, we first examine the relationship between project supervisor emotional healing and project members affect-based trust in their supervisor. As shown in Table 3, we found that project supervisor emotional healing was positively and significantly associated to project members affect-based trust in their supervisor (Model 1, $\beta=0.49$, $p<0.01)$. Secondly, we entered project supervisor emotional healing and project members affect-based trust simultaneously and found that the coefficient of project supervisor emotional healing on project members innovative behavior reduced to $0.47(p<0.01$, Model 5) from $0.62(p<0.01$, Model 3), moreover, affect-base trust is positively related to project members innovative behavior $(\beta=0.49$, $p<0.01$, Model 5). The results show that project members affect-based trust mediates the relationship between project supervisor emotional healing and project members innovative behavior, hypothesis 5 was supported.

To test the mediating effect of cognition-based trust on relationship between project supervisor conceptual skill and project members innovative behavior, we first examine the relationship between project supervisor conceptual skill and project member cognition-based trust. As shown in Table 3, we found that project supervisor conceptual skill was positively and significantly associated to project members cognition-based trust in supervisor (Model 2, $\beta=0.71, p<0.01$ ). Secondly, we entered project supervisor conceptual skill, squared conceptual skill, cognition-based trust and squared cognition-based trust simultaneously and found that the coefficient of squared supervisor conceptual skill on project members innovative behavior reduced to $-0.08(p>0.05$, Model 10) from $-0.16(p<0.01$, Model 7), moreover, squared cognition-base trust is negatively related to project members innovative behavior ( $\beta=-0.11, p<0.05$, Model 10). The results show that project members cognition-based trust in their supervisor mediates the inverted U-shape relationship between supervisor conceptual skill and project member innovative behavior, hypothesis 6 was supported.

\section{Discussion and Conclusions}

\subsection{Research Implications}

Although several studies have examined trust in supervisor as mediator between leadership and individual outcomes, few studies have investigated the different mediating mechanisms of two typical trust in supervisor (affect-based trust and cognition-based trust) between different supervisor 
leadership skill and follower behaviors. Considering affect-based and cognition-based trust in supervisor demonstrates the potential of trust as a different explanatory mechanism linking specific leadership skill and subordinate outcomes. We next discuss the implications of our findings.

First, project supervisor emotional healing has a positively linear impact on project members innovative behavior and project supervisor conceptual skill has an inverted U-shape effect on project innovative behavior. To this point, previous studies have mainly identified how leadership influence individual innovativeness (e.g., Zhang and Bartol, 2010 [42]; Pieterse, Van Knippenberg, Schippers and Stam, 2010 [44]) and most of these studies focused on testing the linear relationship between positive leadership and individual innovativeness. It is worth noting that few previous studies have tested different effects of specific leadership skills on subordinate innovativeness. It is worth considering this point, because leadership includes multiple specific skills that have different effects on individual behaviors [45,46]. By examining the effects of two core leadership skills, emotional healing and conceptual skill on project members innovative behavior, we can be more certain that the effect of emotional healing and conceptual skill are different, more generally, emotional healing has a positive linear impact on project members innovative behavior and there will be an inverted U-shape relationship between conceptual skill and project member innovative behavior. This paper responded to the call that research is needed on whether more specific leadership skills can have differential effects on individual performance and the impact mechanism of such leadership should be examined in future research [47].

Second, another finding is affect-based and cognition-based trust in project supervisor also has differential impact on project members innovative behavior. We inferred so according to general psychological theories and reached similar conclusions investigated by $\mathrm{Ng}$ and Chua (2006) [13]. Ng and Chua (2006) [13] similarly observed that affect-based trust in colleagues linear related to cooperative behavior and cognition-based trust curvilinear related to cooperative behavior. Nevertheless, this paper speculates that differential impact of affect-based and cognition-based trust in project supervisor on project members innovative behavior. This research confirmed the opinions of Chua, Morris and Mor (2012) [48] that affect-based and cognition-based trust in a supervisor might have a differential impact on creativity.

Finally, we found that affect-based trust mediated the effect of project supervisor emotional healing on project members innovative behavior and cognition-based trust mediated the inverted U-shape effect of project supervisor conceptual skill on project members innovative behavior. First, our findings indicate that project supervisor emotional healing lead subordinate to generate affect-based trust through caring manner, then project members will feel safety to express their ideas and receive more feedback from others, which can promote them to generate new useful ideas. Schaubroeck et al. (2011) [8] found that affect-based trust in a supervisor is an important mediator between leadership and outcomes, the results of this paper imply that affect-based trust in a supervisor not only promotes follower innovative behavior but is also a crucial explanatory mechanism between supervisor leadership skill and subordinate innovative behavior, which deepens and complements the understanding of previous studies. Second, our results showed that cognition-based trust in leader mediates the inverted $U$ relationship between project supervisor conceptual skill and project members innovative behavior. Existing research emphasized that the positive effect of a supervisor's competence on innovativeness in an organization [49,50]; however, this research found that cognitive-based trust in a project supervisor plays a role in transferring the positive effect of conceptual skill and the mediating effect of cognition-based trust in a project supervisor is changed from positive to negative with increasing project supervisor conceptual skill. This result implies that high level of conceptual skill may leads project members excessive cognition-based trust in their supervisor which make individual depend on others, then they decrease their effort to solved project-related problems. The conclusion helps us to understand the chain negative effect of a high level of project supervisor conceptual skill. 


\subsection{Practical Implications}

This paper provides some directions on how a project supervisor can promote trust to encourage subordinates' innovative behavior, which can be a driver of sustainable high performance and career success. We concur with arguments of Schaubroeck et al. (2011) [8] and Whitener et al (1998) [51], which stated that supervisors are important antecedent of trust and supervisor's leadership has an indirect effect on subordinate's attitude and behavior via trust. Our findings further draw attention to two crucial concentrations for project supervisor in establishing trust with their followers. First, project supervisor should be concern of the value of emotional healing, which can increase project member's innovative behavior to keep their sustainability. Project supervisor can improve project member affect-based trust by caring project member personal well-being, or recognize and help project member recovery from dilemma. Second, previous research revealed that conceptual skill was positively related to innovative behavior but we found that while moderated conceptual skill benefited individual innovative behavior, excessive conceptual skill may reduce individual innovative behavior. It means that a project supervisor with high level of conceptual skill should, for example, be conscious of probable risks related to consequently. Project supervisor should provide moderate support and assistance to their subordinates to avoid project member form psychological dependence.

\subsection{Limitations}

Despite these contributions, there are some noteworthy limitations in this research. First, common method bias might contaminate our findings, because we collected data of independent variables and mediator from single source. This bias might be a flaw in this article but we believed that this bias has little impact on our findings according to the examination of common method bias proposed by Harman (1967) [52]. We encourage future research to collect data from multiple sources to test hypothesis. Second, we use cross-sectional data to test our hypothesis so that this paper could not test the causal relationship among these constructs. It is reasonable that project member who exhibit high levels of innovative behavior are more likely to obtain support from project supervisor. This possibility will be low because we developed our hypothesis based on previous findings, which provided this article with strong theoretical support. However, additional multi-wave data designs are needed to understand the causal relationship among these constructs. Third, our research only considers trust as a mediator to interpret the relationship between project supervisor leadership behavior and project members' innovative behavior but there may be other moderators influencing the indirect effect of leadership behavior on project member innovative behavior via trust. For example, individuals who are self-focused may associate with low psychological dependence on others [53] (Pitesa and Thau, 2013). It implies that project supervisor conceptual skill may linear positive related to project member subordinate innovative behavior if the one with high level of self-focus. Therefore, future studies can conduct empirical research on considering some moderators (e.g., self-focus, self-efficacy) to explain the mechanism between leadership behavior, trust and innovative behavior.

Author Contributions: Writing: C.-F.L.; Providing case and idea: H.-S.L. \& C.-F.L.; Providing revised advice: C.-C.C.

Funding: This research received no external funding.

Conflicts of Interest: The authors declare no conflict of interest.

\section{References}

1. Sundström, P.; Zika-Viktorsson, A. Organizing for innovation in a product development project: Combining innovative and result oriented ways of working-A case study. Int. J. Proj. Manag. 2009, 27, 745-753. [CrossRef]

2. Scott, S.G.; Bruce, R.A. Determinants of innovative behavior: A path model of individual innovation in the workplace. Acad. Manag. J. 1994, 37, 580-607.

3. Anderson, N.; Potočnik, K.; Zhou, J. Innovation and creativity in organizations a state-of-the-science review, prospective commentary, and guiding framework. J. Manag. 2014, 40, 1297-1333. 
4. Yang, L.R.; Huang, C.F.; Hsu, T.J. Knowledge leadership to improve project and organizational performance. Int. J. Proj. Manag. 2014, 32, 40-53. [CrossRef]

5. Bass, B. Bass \& Stogdill's Handbook of Leadership, 3rd ed.; The Free Press: New York, NY, USA, 1990.

6. Dacher, E.S. Loving openness and the healing relationship. Adv. Mind Body Med. 1999, 15, 32-43.

7. Sturnick, J.A. Healing Leadership. In Insights on Leadership; Spears, L.C., Ed.; John Wiley: New York, NY, USA, 1998; pp. 185-193.

8. Schaubroeck, J.; Lam, S.S.; Peng, A.C. Cognition-based and affect-based trust as mediators of leader behavior influences on team performance. J. Appl. Psychol. 2011, 96, 863-871. [CrossRef] [PubMed]

9. Schaubroeck, J.M.; Peng, A.C.; Hannah, S.T. Developing trust with peers and leaders: Impacts on organizational identification and performance during entry. Acad. Manag. J. 2013, 56, 1148-1168. [CrossRef]

10. Barbuto, J.E.; Hayden, R.W. Testing relationships between servant leadership dimensions and leader member exchange (LMX). J. Leadersh. Educ. 2011, 10, 22-37. [CrossRef]

11. Jeffries, F.L.; Reed, R. Trust and adaptation in relational contracting. Acad. Manag. Rev. 2000, $25,873-882$. [CrossRef]

12. Yang, J.; Mossholder, K.W. Examining the effects of trust in leaders: A bases-and-foci approach. Leadersh. Q. 2010, 21, 50-63. [CrossRef]

13. Ng, K.Y.; Chua RY, J. Do I Contribute More When I Trust More? Differential Effects of Cognition- and Affect-Based Trust. Manag. Organ. Rev. 2006, 2, 43-66. [CrossRef]

14. Burke, C.S.; Sims, D.E.; Lazzara, E.H.; Salas, E. Trust in leadership: A multi-level review and integration. Leadersh. Q. 2007, 18, 606-632. [CrossRef]

15. Dirks, K.T.; Ferrin, D.L. Trust in leadership: Meta-analytic findings and implications for research and practice. J. Appl. Psychol. 2002, 87, 611-628. [CrossRef] [PubMed]

16. Barbuto, J.E.; Wheeler, D.W. Scale Development and Construct Clarification of Servant Leadership. Group Organ. Manag. 2006, 31, 300-326. [CrossRef]

17. Weymes, E. Relationships not leaderships sustain successful organisations. J. Chang. Manag. 2003, 3, 319-331. [CrossRef]

18. Fry, L.W. Toward a theory of spiritual leadership. Leadersh. Q. 2003, 14, 693-727. [CrossRef]

19. Liden, R.C.; Wayne, S.J.; Liao, C.; Meuser, J.D. Servant leadership and serving culture: Influence on individual and unit performance. Acad. Manag. J. 2014, 57, 1434-1452. [CrossRef]

20. Liden, R.C.; Wayne, S.J.; Zhao, H.; Henderson, D. Servant leadership: Development of a multidimensional measure and multi-level assessment. Leadersh. Q. 2008, 19, 161-177. [CrossRef]

21. Grant, A.M.; Berry, J.W. The necessity of others is the mother of invention: Intrinsic and prosocial motivations, perspective taking, and creativity. Acad. Manag. J. 2011, 54, 73-96. [CrossRef]

22. Leban, W.; Zulauf, C. Linking emotional intelligence abilities and transformational leadership styles. Leadersh. Organ. Dev. J. 2004, 25, 554-564. [CrossRef]

23. Amabile, T.M. A model of creativity and innovation in organizations. Res. Organ. Behav. 1988, 10, $123-167$.

24. Kanter, R.M. The middle manager as innovator. Harvard Bus. Rev. 2004, 82, 150-161.

25. Jansen, J.J.; Vera, D.; Crossan, M. Strategic leadership for exploration and exploitation: The moderating role of environmental dynamism. Leadersh. Q. 2009, 20, 5-18. [CrossRef]

26. Amabile, T.M. Creativity and Innovation in Organizations; Harvard Business School: Boston, MA, USA, 1996.

27. Mumford, M.D.; Zaccaro, S.J.; Harding, F.D.; Jacobs, T.O.; Fleishman, E.A. Leadership skills for a changing world: Solving complex social problems. Leadersh. Q. 2000, 11, 11-35. [CrossRef]

28. McAllister, D.J. Affect-and cognition-based trust as foundations for interpersonal cooperation in organizations. Acad. Manag. J. 1995, 38, 24-59.

29. Yang, J.; Mossholder, K.W. Trust in Organizations: A Multi-Bases, Multi-Foci Investigation. In Proceedings of the 21st Annual Meeting of the Society for Industrial and Organizational Psychology, Dallas, TX, USA, May 2006.

30. Hansen, M.H.; Morrow, J.; Batista, J.C. The impact of trust on cooperative membership retention, performance, and satisfaction: An exploratory study. Int. Food Agribus. Manag. Rev. 2002, 5, 41-59. [CrossRef]

31. Colquitt, J.A.; LePine, J.A.; Piccolo, R.F.; Zapata, C.P.; Rich, B.L. Explaining the justice-performance relationship: Trust as exchange deepener or trust as uncertainty reducer? J. Appl. Psychol. 2012, 97, 1-15. [CrossRef] [PubMed] 
32. Amabile, T.M.; Conti, R.; Coon, H.; Lazenby, J.; Herron, M. Assessing the work environment for creativity. Acad. Manag. J. 1996, 39, 1154-1184.

33. Kramer, R.M. Trust and distrust in organizations: Emerging perspectives, enduring questions. Annu. Rev. 1999, 50, 569-598. [CrossRef] [PubMed]

34. Langfred, C.W. Too much of a good thing? Negative effects of high trust and individual autonomy in self-managing teams. Acad. Manag. J. 2004, 47, 385-399.

35. Weber, M. Economy and Society: An Outline of Interpretive Sociology; University of California Press: Berkeley, CA, USA, 1978.

36. Kerr, N.L.; Bruun, S.E. Dispensability of member effort and group motivation losses: Free-rider effects. J. Pers. Soc. Psychol. 1983, 44, 78-94. [CrossRef]

37. Ehrhart, M.G. Leadership and procedural justice climate as antecedents of unit-level organizational citizenship behavior. Pers. Psychol. 2004, 57, 61-94. [CrossRef]

38. Walumbwa, F.O.; Hartnell, C.A.; Oke, A. Servant leadership, procedural justice climate, service climate, employee attitudes, and organizational citizenship behavior: A cross-level investigation. J. Appl. Psychol. 2010, 95, 517. [CrossRef] [PubMed]

39. Pillai, R.; Schriesheim, C.A.; Williams, E.S. Fairness perceptions and trust as mediators for transformational and transactional leadership: A two-sample study. J. Manag. 1999, 25, 897-933. [CrossRef]

40. Podsakoff, P.M.; MacKenzie, S.B.; Moorman, R.H.; Fetter, R. Transformational leader behaviors and their effects on followers' trust in leader, satisfaction, and organizational citizenship behaviors. Leadersh. Q. 1990, 1, 107-142. [CrossRef]

41. Brislin, R. The Wording and Translation of Research Instruments. In Field Methods in Cross Cultural Research; Sage Publications: Beverly Hills, CA, USA, 1986; pp. 159-163.

42. Zhang, X.; Bartol, K.M. Linking empowering leadership and employee creativity: The influence of psychological empowerment, intrinsic motivation, and creative process engagement. Acad. Manag. J. 2010, 53, 107-128. [CrossRef]

43. Zhang, H.; Kwan, H.K.; Zhang, X.; Wu, L.Z. High Core Self-Evaluators Maintain Creativity A Motivational Model of Abusive Supervision. J. Manag. 2012, 40, 1151-1174.

44. Pieterse, A.N.; Van Knippenberg, D.; Schippers, M.; Stam, D. Transformational and transactional leadership and innovative behavior: The moderating role of psychological empowerment. J. Organ. Behav. 2010, 31, 609-623. [CrossRef]

45. Mahsud, R.; Yukl, G.; Prussia, G. Leader empathy, ethical leadership, and relations-oriented behaviors as antecedents of leader-member exchange quality. J. Manag. Psychol. 2010, 25, 561-577. [CrossRef]

46. Yukl, G. Effective leadership behavior: What we know and what questions need more attention. Acad. Manag. Perspect. 2012, 26, 66-85. [CrossRef]

47. Morgeson, F.P.; DeRue, D.S.; Karam, E.P. Leadership in teams: A functional approach to understanding leadership structures and processes. J. Manag. 2010, 36, 5-39. [CrossRef]

48. Chua, R.Y.; Morris, M.W.; Mor, S. Collaborating across cultures: Cultural metacognition and affect-based trust in creative collaboration. Organ. Behav. Hum. Decis. Proc. 2012, 118, 116-131. [CrossRef]

49. Halbesleben, J.R.; Novicevic, M.M.; Harvey, M.G.; Buckley, M.R. Awareness of temporal complexity in leadership of creativity and innovation: A competency-based model. Leadersh. Q. 2003, 14, 433-454. [CrossRef]

50. Amabile, T.M.; Schatzel, E.A.; Moneta, G.B.; Kramer, S.J. Leader behaviors and the work environment for creativity: Perceived leader support. Leadersh. Q. 2004, 15, 5-32. [CrossRef]

51. Whitener, E.M.; Brodt, S.E.; Korsgaard, M.A.; Werner, J.M. Managers as initiators of trust: An exchange relationship framework for understanding managerial trustworthy behavior. Acad. Manag. Rev. 1998, 23, 513-530. [CrossRef]

52. Harman, H.H. Modern Factor Analysis, 2nd ed.; University of Chicago Press: Chicago, IL, USA, 1967.

53. Pitesa, M.; Thau, S. Compliant sinners, obstinate saints: How power and self-focus determine the effectiveness of social influences in ethical decision making. Acad. Manag. J. 2013, 56, 635-658. [CrossRef]

(C) 2018 by the authors. Licensee MDPI, Basel, Switzerland. This article is an open access article distributed under the terms and conditions of the Creative Commons Attribution (CC BY) license (http:/ / creativecommons.org/licenses/by/4.0/). 